Journal of

Ecology 2007

95, 65-78

\title{
Niche pre-emption increases with species richness in experimental plant communities
}

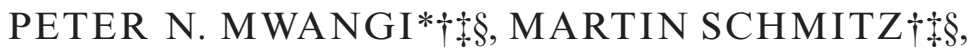 \\ CHRISTOPH SCHERBER $\S$, CHRISTIANE ROSCHER $\ddagger$, \\ JENS SCHUMACHER \\ WOLFGANG W. WEISSER $\S$ and BERNHARD SCHMID $†$ \\ $\dagger$ Institute of Environmental Sciences, Zurich University, Winterthurerstrasse 190, CH-8057 Zurich, Switzerland, \\ $\$$ Max Planck Institute for Biogeochemistry, Hans-Knoll Strasse 10, D-07745 Jena, Germany, §Institute of Ecology, \\ Jena University, Dornburger Strasse 159, D-07743 Jena, Germany, and $\mid$ Institute of Plant Sciences, ETH Zentrum, \\ Universitätstrasse 2, CH-8092 Zurich, Switzerland
}

\begin{abstract}
Summary
In plant communities, invasion resistance may increase with diversity because empty niche space decreases simultaneously. However, it is not clear if this only applies to exotic species or also to native species arriving at a site with few other native species during community assembly. We tested the latter by transplanting four native species into experimental grassland communities varying in species richness form 1-16 (-60) species. In addition, we tested the hypothesis that invasion is less successful if the invading species belongs to a functional group that is already present in the community. The test invaders included a grass species (Festuca pratensis, FP), a short (Plantago lanceolata, PL) and a tall herb species (Knautia arvensis, KA), and a legume species (Trifolium pratense, TP). The same four functional groups also occurred alone or in all possible combinations in the different experimental communities. The overall performance of the transplants was negatively related to the logarithm of the species richness of host communities. Plant biomass declined by $58 \%, 90 \%, 84 \%$ and $62 \%$ in FP, PL, KA and TP, respectively, from monocultures to 16-species mixtures, indicating lower invasiveness of the two herbs than of the grass and the legume. Resident grasses showed a strong negative effect on the performance of all test invaders, whereas resident small and tall herbs had neutral, and resident legumes had positive effects. The case of the legumes indicates that contributions to invasion resistance need not parallel invasiveness. Communities containing resident species of only one functional group were most inhibitive to transplants of the same functional group. These results indicate that invasion resistance of experimental plant communities is related to the degree of niche overlap between resident species and invaders. This niche overlap can be high due to generally low amounts of empty niche space in species-rich resident communities or due to the occurrence of the same functional group as the one of the invader in the resident community. Stronger within- than between-functional-group invasion resistance may be the key mechanism underlying diversity effects on invasion resistance in grassland and other ecosystems at large.
\end{abstract}

Key-words: diversity effects, invasion resistance, invasiveness, niche overlap, phytometers, plant functional groups, The Jena Experiment

Journal of Ecology (2007) 95, 65-78

doi: 10.1111/j.1365-2745.2006.01189.x

(C) 2006 The Authors Journal compilation (C) 2006 British Ecological Society
Correspondence: Bernhard Schmid (tel. +41 44 6355205; fax +41 44 6355711; e-mail bschmid@uwinst.unizh.ch).

*Present address: Department of Botany, Jomo Kenyatta University of Agriculture and Technology, PO Box 62000-00200, Nairobi, Kenya. 
66

P. N. Mwangi et al.

\section{Introduction}

Understanding the mechanisms behind the relationship between resident species richness and the establishment of non-resident species (i.e. invaders in the broad sense) in natural communities is a major goal in ecology. This relationship has potential applications in conservation, restoration and prediction of community invasion resistance. Elton (1958) and Levine \& D'Antonio (1999) provide evidence for a generally negative relationship between diversity and the likelihood that an intruder will be able to establish itself in a community. Such relationships have been found in a large number of experimental studies using temperate plant communities (Tilman 1997; Knops et al. 1999; Joshi et al. 2000; Naeem et al. 2000; Prieur-Richard et al. 2000; Diemer \& Schmid 2001; Kennedy et al. 2002; Pfisterer et al. 2004). In contrast, observational studies, which necessarily assess invasion by exotic invaders, often report higher numbers of invading species in species-rich than in species-poor plant communities (Stohlgren et al. 1999; Stadler et al. 2000; Pysek et al. 2002; Stohlgren et al. 2002), though Stohlgren et al. (1999) found the opposite at one site in their study. The results of observational studies may be attributed to uncontrolled extrinsic factors, whose effect on native and exotic species is the same (Stohlgren et al. 1999; Levine 2000; Shea \& Chesson 2002). Additionally, observational studies mostly analyse the number of invading species (e.g. Stohlgren et al. 1999; Meiners et al. 2004), whereas many experimental studies also assess the performance of particular invaders (see, e.g. Prieur-Richard et al. 2000; Diemer \& Schmid 2001; Hector et al. 2001).

In most cases, species richness is the only component of diversity manipulated in experimental studies (e.g. Prieur-Richard et al. 2000; Troumbis et al. 2002), though some studies have demonstrated the importance of functional diversity in competitive suppression of invaders (Crawley et al. 1999; Hector et al. 2001; Prieur-Richard et al. 2002; Xu et al. 2004; Fargione \& Tilman 2005). Functional groups are sets of species (not necessarily taxonomic) that show close similarities in traits related to ecosystem functioning, e.g. traits related to resource uptake and biomass production. Increasing evidence suggests that the influence of functional diversity in a community might be more important than pure species richness (Diaz \& Cabido 2001; Garnier et al. 2004; Heemsbergen et al. 2004; Petchey et al. 2004).

It is supposed that empty niche space (Hutchinson 1957) declines with increasing species richness in a community (MacArthur 1970). As a consequence, species-rich communities can utilize the total resources available in a biotope more completely than do speciespoor communities (e.g. Scherer-Lorenzen et al. 2003; Dimitrakopoulos \& Schmid 2004), thereby preempting resources for potential invaders (Tilman 1999;

Hector et al. 2001; Fargione et al. 2003). This effect (c) 2006 The Authors Journal compilation Ecological Society, Journal of Ecology 95, 65-78 occurs because, generally, an increase in species richness should also increase functional richness, suggesting that the number of functional groups in an experimental community may be a good predictor of these diversity effects. Conversely, the effect should be minimal if species richness is increased without increasing the number of functional groups at the same time. In addition, a community should be more resistant to invaders belonging to functional groups already present among the resident species (e.g. Fargione et al. 2003; Turnbull et al. 2005).

In most cases, invasion studies compare a set of species used as test invaders with a separate set of species used as residents of host communities (Tilman 1997; Knops et al. 1999; Hector et al. 2001; PrieurRichard et al. 2002; Fargione et al. 2003; Pfisterer et al. 2004; but see Turnbull et al. 2005). This approach mimics biological invasions into communities by exotic species. For example, the average competitive ability of exotic invaders may change with diversity (e.g. Bossdorf et al. 2004; Colautti et al. 2004, Vila \& Weiner 2004; Hierro et al. 2005). Here we do not analyse exotic species invasions but rather invasion as a process of community assembly within a pool of native species. In this case, because the host communities and invaders belong to the same species pool, it is possible to distinguish between the invasiveness of a particular species or functional group as an invader and its contribution to invasion resistance of the host community within the same experiment.

Using this approach, we selected four native species representative of four functional groups used in a biodiversity experiment as test invaders or 'phytometers'. Specifically, we wanted to find out: (i) if increasing species richness or number of functional groups in plant communities suppresses the performance of invaders; (ii) whether the presence of a particular functional group in a host community enhances suppression of the test invaders; and (iii) whether the test invaders are most suppressed by host communities containing species belonging to the same functional group.

\section{Materials and methods}

Our study was part of a large biodiversity experiment, The Jena Experiment in Germany $\left(50^{\circ} 55^{\prime} \mathrm{N}, 11^{\circ} 35^{\prime} \mathrm{E}\right.$, $130 \mathrm{~m}$ altitude). This experiment was established in May 2002 on a former agricultural field in the flood plain of the Saale river (Roscher et al. 2004). Plant communities were assembled by constrained random selection from a pool of 60 species typical to Central European mesophilic grasslands. The species were categorized into the four functional groups: grasses (16 species), small herbs (12 species), tall herbs ( 20 species), and legumes ( 12 species), based on multivariate analyses of their traits (Roscher et al. 2004). Analysed traits included growth form (six binary traits), lateral clonal spread, height of vegetative and flowering plant, leaf size, depth and type of root system, life cycle, seasonality 
Niche pre-emption and invasion resistance
(C) 2006 The Authors Journal compilation (C) 2006 British Ecological Society, Journal of Ecology 95, 65-78 of foliage, onset and duration of flowering and nitrogen fixation. Seventy-eight plots, each measuring $20 \times 20 \mathrm{~m}$, were sown with one, two, four, eight or 16 species. A factorial design was formed with all possible species richness $\times$ functional group richness mixtures. At each level of species richness, 16 replicate mixtures with different species composition were established, except at the highest level with 14 replicates only. Four additional large plots contained mixtures of all 60 species in the pool. The field was partitioned into four blocks following a gradient in soil characteristics perpendicular to the river (Roscher et al. 2004). The plots were mowed twice a year (June and September), as is typical for this type of grassland ecosystem, and weeded twice a year to maintain the original species composition. Mowing and weeding were done block-wise such that these management effects could be accounted for with the block term in statistical analysis.

Our test invaders were pre-grown phytometer individuals of four species that also occurred in a large number of experimental communities as resident species. Clements \& Goldsmith (1924) introduced the term 'phytometer' for test plants that were used to measure environmental factors. Each of the four species belonged to a functional group used in the experiment: Festuca pratensis Huds. (grass), Plantago lanceolata L. (small herb), Knautia arvensis L. (tall herb) and Trifolium pratense L. (legume). They are all perennial plant species, form clearly defined compact individuals, and are relatively easy to transplant.

In mid-March 2003, we germinated the phytometers on moist filter paper in a glasshouse. Individual seedlings were planted in 132- $\mathrm{cm}^{3}$ cells of potting trays filled with a soil-compost-perlite mixture $(3: 2: 1$ in terms of volumes), and were exposed to a 14 -hour light regime with $22{ }^{\circ} \mathrm{C}$ day temperature and $15^{\circ} \mathrm{C}$ night temperatures. In mid-April 2003, most of the plants had four to seven leaves. We placed them outside the glasshouse for hardening and 1 week later transplanted them into the experimental communities. Five phytometer individuals of each test species were randomly allocated to positions at $28-\mathrm{cm}$ intervals in a $2 \times 2-\mathrm{m}$ subplot within each large plot and their initial size determined by counting the number of leaves and number of ramets (the latter only for $F$. pratense and $T$. pratense). Transplanted phytometers were marked by fixing numbered plastic labels next to the plants to ease identification during data collection.

In mid-August, in addition to counting the number of leaves, we measured the maximum height of the phytometers. For T. pratense and F. pratensis, we also counted the number of ramets as before. We calculated the relative growth rate of the transplants using the formula

$\mathrm{RGR}=\left(\ln l_{t 2}-\ln l_{t 1}\right) / d$,

where $l_{t 2}$ is the mean number of leaves in August, $l_{t 1}$ is the mean number of leaves in April and $d$ is the length of time interval in days (Harper 1977). As a measure of plant fitness, in August, we also counted the number of inflorescences of $P$. lanceolata and $T$. pratense transplants. No individuals of $F$. pratensis or $K$. arvensis were flowering at this time. In the last week of August 2003, shortly before mowing, transplants were cut at $3 \mathrm{~cm}$ above the ground and dried at $70{ }^{\circ} \mathrm{C}$ for at least 48 hours to determine the average biomass of each transplant species per plot. In early June 2004, we once again measured the height of the transplants, counted the number of inflorescences in P. lanceolata and $T$. pratense, which were flowering at this time, and harvested the transplants per species per plot to determine the average above-ground biomass as described above.

Before each harvest, we determined the leaf area index (LAI) of the resident community in an undisturbed area next to the phytometers using an LAI-2000 Plant Canopy Analyser (LI-COR Inc., Lincoln, Nebraska, USA).

\section{STATISTICAL ANALYSIS}

We used general linear models with sequential sum of squares (Type I) for data analysis using Genstat 6th Edition, Release 6.2 (Payne et al. 2002). As individual plants were pseudo-replicates within plots, we analysed means of the response variables plant biomass, plant height, number of leaves and relative growth rate. The data were transformed if residuals showed deviation from the normal distribution. According to the experimental design, the analysis of variance (ANOVA) model consisted of the terms block, sown species richness (partitioned into log-linear contrast and deviation from log-linear contrast), functional group richness, species composition, phytometer species and phytometer species-diversity interactions. Separate contrasts for the presence/absence of each functional group and their interactions with species richness were tested in alternative models. Similarly, separate contrasts were made to compare each phytometer species and its interactions with diversity terms against the other three phytometer species. The diversity terms (species richness, functional group richness, presence of particular functional groups) had to be tested at the between-plot level $($ Error $=$ composition $)$, whereas phytometer terms and their interactions with diversity terms could be tested at the within-plot level (Schmid et al. 2002). We also analysed the data of each phytometer species separately. To determine if the effect of diversity terms was related to a change in the leaf-area index (LAI) of the community we did post-hoc analyses with LAI as a covariate. In addition, LAI was tested as a dependent variable itself, using the between-plot ANOVA as explained above.

To test whether the phytometer species were more affected by their own than by other functional groups, we used a reduced data set of communities with only one functional group ( $n=34$ plots). To do this, the resident $\times$ transplant functional group interaction was decomposed into a 'home vs. away' contrast and 
P. N. Mwangi et al. remainder (taking all 'away' treatment combinations together; see Table 3). To illustrate the home vs. away contrast we use an equivalent of the relative-neighboureffect of Markham \& Chanway (1996), using the formula $\left(P_{h}-P_{a}\right) / \max \left(P_{h}, P_{a}\right)$. Here, $P_{h}$ is the performance (e.g. biomass) of phytometers in communities with their own functional group (home), $P_{a}$ the performance in communities with other functional groups (away) and $\max \left(P_{h}, P_{a}\right)$ is the larger of the two.

\section{Results}

\section{EFFECTS OF SPECIES RICHNESS AND FUNCTIONAL RICHNESS}

Except for plant height in P. lanceolata and $K$. arvensis, the measured morphological variables of phytometers were highly correlated with their above-ground biomass (Table 1), indicating that the latter is a good measure of overall phytometer performance.

At the first harvest in summer 2003, i.e. 4 months after transplanting, the performance of phytometer individuals was negatively related to the logarithm of sown species richness (reduced number of leaves or number of ramets, reduced biomass and reduced growth rate, Fig. 1a,c,d and Table 2a). The height of the phytometers was, however, not affected and even increased with the logarithm of species richness in one of the phytometer species ( $F$. pratensis; $F_{1,70}=9.30$, $P<0.01$ in separate analysis), suggesting a typical allometric response to increased competition for light (etiolation), i.e. a faster increase in height, independent of size (Fig. 1b, Table 2a; see also lower correlations of plant height than of other variables with biomass in Table 1). The length of the leaves in $F$. pratensis also increased with increasing species richness $\left(F_{1,73}=\right.$ 15.64, $P<0.001)$. The influence of resident species richness on phytometer performance varied among phytometer species; the herbs ( $P$. lanceolata and $K$. arvensis) were more strongly affected than the grass (F. pratensis) and the legume (T. pratense) (see species richness $\times$ phytometer species (PS) interaction in Table 2a). The negative effect of species richness on phytometer above-ground biomass was still significant in spring $2004\left(F_{1,73}=27.80, P<0.001\right.$; Fig. 2 b), but again plant height was not affected by species richness $\left(F_{1,73}=1.19, P<0.172\right.$; Fig. 2a).
Functional richness had no effect on the performance of the phytometers after controlling for species richness in both seasons $(P>0.05)$. By contrast, if fitted before species richness, functional richness also had significant negative effects on all phytometer variables except height (above-ground plant biomass, $F_{1,67}=4.74, P=0.03$; plant height, $F_{1,67}=1.38, P=$ 0.24 ; number of leaves, $F_{1,67}=7.13, P=0.01$; growth rate, $F_{1,67}=6.12, P=0.01$; Fig. $1 \mathrm{e}-\mathrm{h}$ ), and in addition the species richness effects remained significant $(P<0.05)$ except for plant height, as before. The pattern was the same in spring 2004 (Fig. 2c,d). This highlights the importance of species richness even if functional richness in statistical terms is 'held constant', i.e. the species richness effect remains negative within a particular level of functional richness.

Separate analyses showed that increasing species richness (log-scale) led to a significant reduction in number of inflorescences per plant in $P$. lanceolata $\left(F_{1,70}=25.58, P<0.001\right)$ and $T$. pratense $\left(F_{1,69}=6.07\right.$, $P=0.01)$, the two phytometer species that flowered before the first harvest in August 2003 (Fig. 3a). The same negative effect of species richness on number of inflorescences per plant was observed in P. lanceolata $\left(F_{1,69}=18.31, P<0.001\right)$ and $K$. arvensis $\left(F_{1,68}=18.88\right.$, $P<0.001$ ) in spring 2004 (Fig. 3a). Again, the effect of functional richness on the number of inflorescences was not significant after controlling for species richness, but it was highly significant if fitted first (summer 2003: P. lanceolata, $F_{1,70}=11.15, P<0.001 ; T$. pratense, $F_{1,69}=$ 6.13, $P=0.016$; spring 2004: $P$. lanceolata, $F_{1,69}=12.04$, $P<0.001 ; K$ arvensis, $F_{1,68}=14.71, P<0.001$; Fig. $\left.3 b\right)$, with the effect of species richness fitted afterwards again remaining significant $(P<0.01)$.

\section{EFFECTS OF THE PRESENCE OF PARTICULAR FUNCTIONAL GROUPS}

The presence of grasses or legumes in the host communities had significant overall effects on phytometers, but this was not the case for the other two functional groups (Table 2a). Grasses significantly reduced number of modules (number of leaves or number of ramets), above-ground biomass, and growth rate of all the phytometer species (Table 2a), as well as number of inflorescences in $P$. lanceolata in summer $2003\left(F_{1,68}\right.$ $=5.66, P=0.02)$ and spring $2004\left(F_{1,67}=7.56, P=\right.$
(C) 2006 The Authors Journal compilation (C) 2006 British Ecological Society, Journal of Ecology 95, 65-78
Table 1 Partial correlation of phytometer vegetative and reproductive traits measured in summer 2003 with above-ground biomass harvested at the same time. Significance levels are, ${ }^{*} P<0.05,{ }^{*} P<0.01,{ }^{* *} P<0.001$

\begin{tabular}{|c|c|c|c|c|}
\hline Plant trait & $\begin{array}{l}F \text {. pratense } \\
(n=71)\end{array}$ & $\begin{array}{l}\text { P. lanceolata } \\
(n=78)\end{array}$ & $\begin{array}{l}K . \text { arvensis } \\
(n=76)\end{array}$ & $\begin{array}{l}\text { T. pratense } \\
(n=68)\end{array}$ \\
\hline Number of leaves & $0.919 * * *$ & $0.887 * * *$ & $0.855^{* * *}$ & $0.776 * * *$ \\
\hline Number of ramets & $0.904 * * *$ & - & - & $0.866 * * *$ \\
\hline Height & $0.467 * * *$ & $0.128^{\mathrm{NS}}$ & $0.228 *$ & $0.415^{* * *}$ \\
\hline Number of flowers & - & $0.974 * * *$ & - & $0.938 * * *$ \\
\hline Relative growth rate & $0.804 * * *$ & $0.610 * *$ & $0.720 * * *$ & $0.680 * * *$ \\
\hline
\end{tabular}


Niche pre-emption and invasion resistance
(C) 2006 The Authors Journal compilation (C) 2006 British Ecological Society, Journal of Ecology 95, 65-78

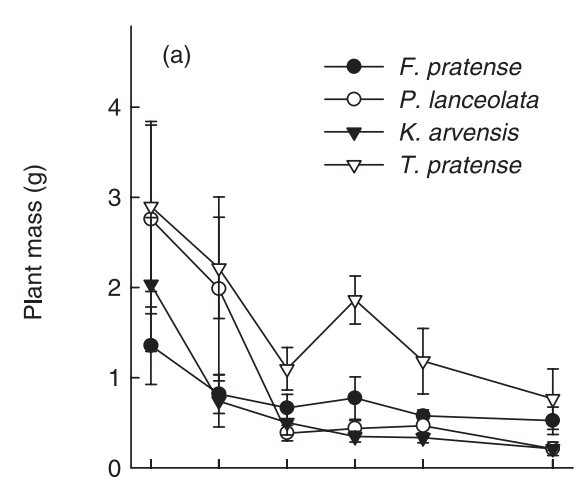

(e)
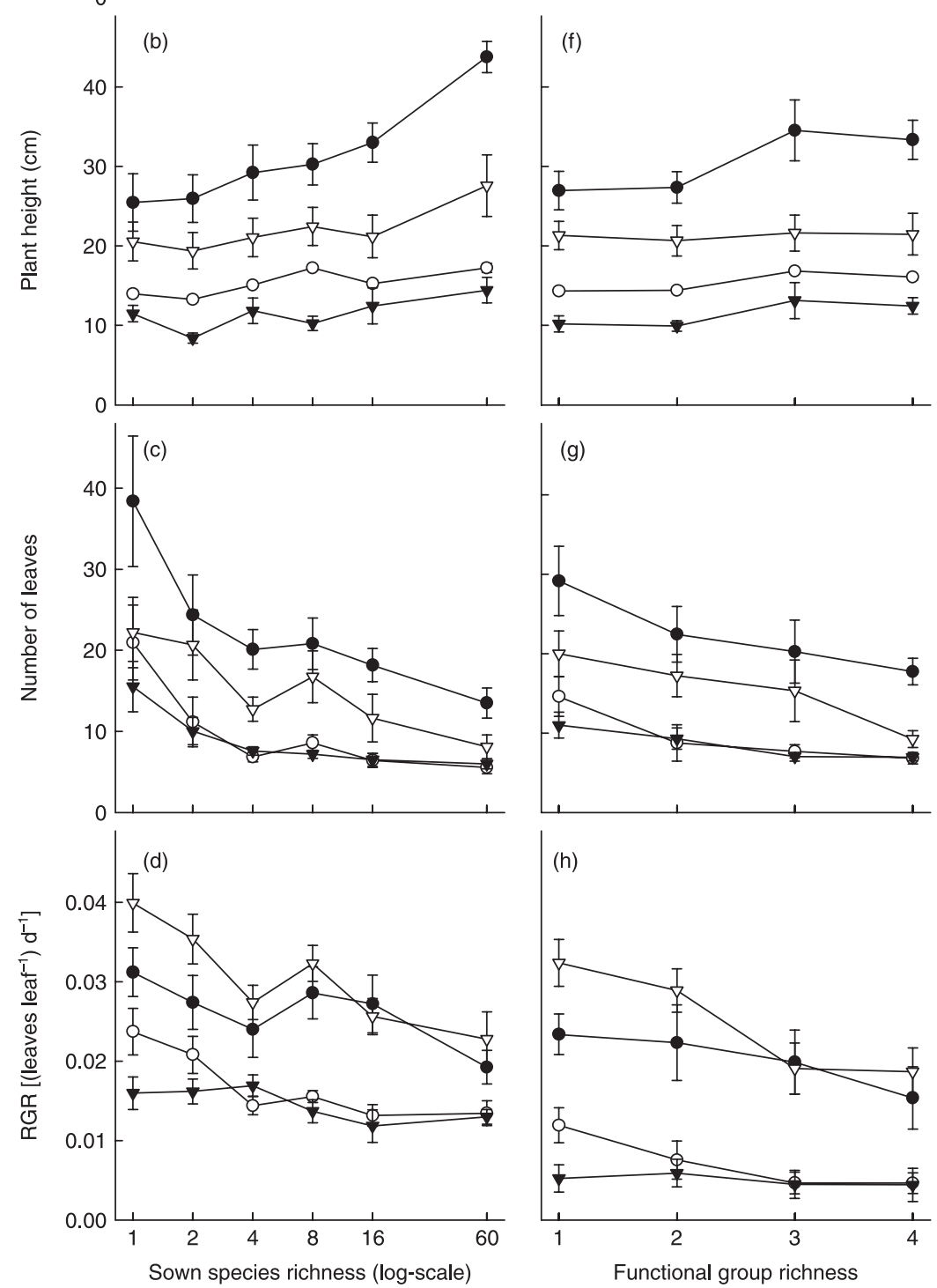

Fig. 1 Effect of plant species richness $(\mathrm{a}-\mathrm{d})$ and functional group richness $(\mathrm{e}-\mathrm{h})$ on performance of four transplanted phytometer species in the first season (summer 2003). Points and vertical bars represent means \pm 1 standard error. All panels use the legend in panel (a).

0.008). For example, in summer 2003, the average biomass of an individual phytometer (all species together) was $0.8 \mathrm{~g}$ in plots with grasses compared with $1.9 \mathrm{~g}$ in plots without grasses (Fig. 4). In spring 2004, the figures were $3.5 \mathrm{~g}$ and $10.8 \mathrm{~g}$ for plots with and without grasses, respectively. The presence of legumes had an overall significantly positive effect on the performance of the phytometer species (Table 2a, Figs 4 and 5). Separate analysis for each phytometer, however, revealed that the presence of legumes actually reduced above-ground biomass of the legume phytometer, $T$. pratense, at least in spring $2004\left(F_{1,61}=8.97\right.$, $P=0.004)$. The negative effect of legume presence on the legume phytometer as opposed to a positive effect on the other phytometers is also evident in the significant contrast interaction legume presence $\times T$. pratense $(\mathrm{LG} \times \mathrm{TP}$ in Table $2 \mathrm{~b})$ and when inspecting the last rows in Figs 4 and 5. 
70

P. N. Mwangi et al.
Table 2a Summary of analyses of variance of the performance of the four phytometer species in summer 2003. Residual d.f. are ${ }^{\mathrm{a}} 225$ and total $^{\mathrm{b}} 308$ for number of leaves and plant height and ${ }^{\mathrm{a}} 240$ and total ${ }^{\mathrm{b}} 327$ for growth rate. Diversity is represented by a loglinear contrast (SR) and the deviation from this contrast. The phytometer species (PS) at the same time represents the functional group of the phytometer. Due to hierarchical design of the experiment, the terms above composition are tested at plot-level error term, i.e. composition. The terms presence of functional groups and their interaction with SR were added alternatively because they are intrinsically related, same communities contained presence/absence of different groups. PS and SR x PS was tested against within-plot error (residual). Significance levels are $* P<0.05 ; * * P<0.01 ; * * *<0.001$

\begin{tabular}{|c|c|c|c|c|c|c|c|c|c|}
\hline \multirow[b]{2}{*}{ Source } & \multirow[b]{2}{*}{ d.f. } & \multicolumn{2}{|c|}{ Biomass } & \multicolumn{2}{|l|}{ Leaves } & \multicolumn{2}{|c|}{ Height } & \multicolumn{2}{|c|}{ Growth rate } \\
\hline & & MS & $F$ & MS & $F$ & MS & $F$ & MS & $F$ \\
\hline Block & 3 & 6.23 & 2.63 & 1.06 & 1.23 & 0.79 & 1.61 & $<0.01$ & 1.53 \\
\hline Species richness (SR) & 1 & 22.22 & $9.39 * *$ & 14.84 & $17.23 * * *$ & 1.17 & 2.36 & $<0.01$ & $13.59 * * *$ \\
\hline Deviation & 3 & 5.17 & 2.18 & 1.26 & 1.46 & 0.26 & 0.53 & $<0.01$ & 0.71 \\
\hline Composition & 70 & 2.37 & $3.28 * * *$ & 0.86 & $4.28 * * *$ & 0.49 & $4.30 * * *$ & $<0.01$ & $3.07 * * *$ \\
\hline Grasses (GR) & 1 & 19.52 & $9.25 * *$ & 3.20 & $3.89 *$ & 4.93 & $11.66^{* *}$ & $<0.01$ & $4.41 *$ \\
\hline $\mathrm{SR} \times \mathrm{GR}$ & 1 & 2.72 & 1.29 & 1.10 & 1.33 & 0.93 & 2.19 & $<0.01$ & 2.98 \\
\hline Composition & 68 & 2.11 & $2.89 * * *$ & 0.82 & $4.21 * * *$ & 0.42 & $3.82 * * *$ & $<0.01$ & $3.11 * * *$ \\
\hline Short-herbs (SH) & 1 & 3.33 & 1.41 & 0.15 & 0.17 & 1.06 & 2.19 & $<0.01$ & 0.46 \\
\hline $\mathrm{SR} \times \mathrm{SH}$ & 1 & 1.60 & 0.68 & 0.00 & $<0.01$ & 0.77 & 1.59 & $<0.01$ & 0.99 \\
\hline Composition & 68 & 2.37 & $3.39 * * *$ & 0.88 & $4.36 * * *$ & 0.48 & $4.13 * * *$ & $<0.01$ & $3.07 * * *$ \\
\hline Tall-herbs (TH) & 1 & 4.22 & 1.78 & 1.27 & 1.46 & 0.70 & 1.41 & $<0.01$ & 0.04 \\
\hline $\mathrm{SR} \times \mathrm{TH}$ & 1 & 0.06 & 0.02 & 0.08 & 0.09 & 0.31 & 0.62 & $<0.01$ & $<0.01$ \\
\hline Composition & 68 & 2.38 & $3.31 * * *$ & 0.87 & $4.23 * * *$ & 0.49 & $4.38 * * *$ & $<0.01$ & $3.12 * * *$ \\
\hline Legumes (LG) & 1 & 13.15 & $5.86^{*}$ & 0.82 & 0.94 & 7.18 & $17.88 * * *$ & $<0.01$ & $<0.01$ \\
\hline $\mathrm{SR} \times \mathrm{LG}$ & 1 & 0.03 & 0.01 & 0.35 & 0.41 & 0.08 & 0.20 & $<0.01$ & 0.17 \\
\hline Composition & 68 & 2.24 & $3.29 * * *$ & 0.87 & $4.76 * * *$ & 0.40 & $3.64^{* * *}$ & $<0.01$ & $3.31 * * *$ \\
\hline Phytometer species (PS) & 3 & 10.44 & $14.47 * *$ & 14.82 & $73.58^{* *}$ & 13.31 & $115.84^{* *}$ & $<0.01$ & $82.60 * * *$ \\
\hline $\mathrm{SR} \times \mathrm{PS}$ & 3 & 2.07 & $2.88^{*}$ & 0.25 & 1.26 & 0.17 & 1.45 & $<0.01$ & $3.08^{*}$ \\
\hline Residual & $216^{\mathrm{a}}$ & 0.72 & & 0.20 & & 0.11 & & $<0.01$ & \\
\hline Total & $299^{b}$ & 1.39 & & 0.56 & & 0.34 & & $<0.01$ & \\
\hline
\end{tabular}

There were no significant interactions between species richness and the effect of presence of particular functional groups in the communities on phytometer performance. We mention this explicitly because such interactions might be expected if the sown proportion of a functional group would influence invasion resistance; where present, the proportion of a functional group decreases with increasing species richness.

In both seasons, the leaf area index (LAI) of the resident community increased with the logarithm of species richness (August 2003, $F_{1,68}=6.42, P=0.014$; May 2004, $F_{1,70}=6.70, P=0.012$ ) but was not affected by functional richness. Although there was no effect of the presence of any functional group on LAI in August 2003, in May 2004, LAI was high in mixtures containing legumes $\left(F_{1,68}=28.01, P<0.001\right)$ and low in mixtures containing small herbs $\left(F_{1,68}=6.52, P<0.013\right)$. This suggests that below-ground competition may be responsible for the observed high suppression of phytometers in communities containing grasses. As a covariate, in August 2003, LAI had significant negative effects on number of leaves and growth rate, positive effects on plant height $(P<0.05)$ but neutral effects on biomass of the phytometers. In May 2004, however, LAI had negative effects on above-ground biomass, plant height and number of ramets of the phytometers $(P<0.05)$. However, where present, the effects of LAI did not explain the significant effects of species richness; that is, species richness effects remained significant after controlling for the effect of LAI.

\section{EFFECTS OF THE FUNCTIONAL GROUP OF THE PHYTOMETER SPECIES}

As suggested by hypothesis (iii) in the Introduction, comparing the suppression of invaders by communities containing different functional groups is not the same as looking at the performance of invaders belonging to different functional groups. In the first case (hypotheses (i) and (ii) in the Introduction), the panels in Figs 4 and 5 are compared row-wise, in the second case they are compared column-wise. If the two approaches are combined, the performance of particular phytometer species in assemblages containing only species of its functional group can be compared with its performance in assemblages containing only the other functional groups (-1 diagonal in Figs 4 and 5). We refer to this as a 'home vs. away' contrast (see, e.g. Joshi et al. 2001; Turnbull et al. 2005), for which hypothesis (iii) predicts a particularly strong negative effect.

The effect of different single-functional-group assemblages on number of modules (leaves or ramets), above-ground biomass and growth rate of the phytometers was similar (Table 3). However, the height of the phytometers significantly differed among these assemblages: it increased from grass $<$ small-herb $<$ tallherb $<$ legume communities, suggesting that competition for light increased in this order. Overall, the two herbaceous phytometer species were least affected by differences between these one functional group assemblages, whereas the grass (F. pratensis) and the legume
(C) 2006 The Author Journal compilation Ecological Society, Journal of Ecology 95, 65-78 
71

Niche pre-emption and invasion

resistance
C 2006 The Authors Journal compilation (C) 2006 British Ecological Society, Journal of Ecology $\mathbf{9 5}, 65-78$
Table 2b Summary of analyses of variance of contrasts of phytometer species and their interaction with the diversity terms. Residual d.f. are ${ }^{a}=219$ for number of leaves and plant height and ${ }^{a}=234$ for growth rate. Contrasts for each phytometer species were added alternatively into model in table $2 \mathrm{a}$ and tested against their respective residuals. Abbreviations not included in table $2 \mathrm{a}$ are $; \mathrm{FP}=$ Festuca pratensis, $\mathrm{PL}=$ Plantago lanceolata, $\mathrm{KA}=$ Knautia arvensis, $\mathrm{TP}=$ Trifolium pratense, for the phytometer species

\begin{tabular}{|c|c|c|c|c|c|c|c|c|c|}
\hline \multirow[b]{2}{*}{ Source of variation } & \multirow[b]{2}{*}{ d.f. } & \multicolumn{2}{|c|}{ Biomass } & \multicolumn{2}{|l|}{ Leaves } & \multicolumn{2}{|l|}{ Height } & \multicolumn{2}{|c|}{ Growth rate } \\
\hline & & MS & $F$ & MS & $F$ & MS & $F$ & MS & $F$ \\
\hline FP & 1 & $<0.01$ & $<0.01$ & 33.52 & $171.49 * *$ & 25.57 & $231.06 * *$ & $<0.01$ & $36.33^{* * *}$ \\
\hline $\mathrm{SR} \times \mathrm{FP}$ & 1 & 3.55 & $4.86^{*}$ & 0.42 & 2.14 & 0.50 & $4.49 *$ & $<0.01$ & 2.26 \\
\hline $\mathrm{GR} \times \mathrm{FP}$ & 1 & 0.19 & 0.26 & 1.46 & $7.48 * *$ & 0.01 & 0.08 & $<0.01$ & $18.02 * * *$ \\
\hline $\mathrm{GR} \times \mathrm{PS}$ & 2 & 0.23 & 0.32 & 0.52 & 2.68 & 0.34 & $3.04 *$ & $<0.01$ & $3.89 *$ \\
\hline $\mathrm{SR} \times \mathrm{GR} \times \mathrm{FP}$ & 1 & 0.38 & 0.52 & 0.00 & 0.02 & 0.15 & 1.31 & $<0.01$ & 2.26 \\
\hline $\mathrm{SR} \times \mathrm{GR} \times \mathrm{PS}$ & 2 & 0.64 & 0.88 & 0.00 & 0.00 & 0.40 & $3.57 *$ & $<0.01$ & 0.13 \\
\hline Residual & $210^{\mathrm{a}}$ & 0.73 & & 0.20 & & 0.11 & & $<0.01$ & 0.61 \\
\hline PL & 1 & 1.49 & 2.13 & 12.46 & $61.43 * *$ & 2.15 & $18.44^{* *}$ & $<0.01$ & $50.16 * * *$ \\
\hline $\mathrm{SR} \times \mathrm{PL}$ & 1 & 3.68 & $5.27^{*}$ & 0.53 & 2.60 & 0.04 & 0.34 & $<0.01$ & 0.77 \\
\hline $\mathrm{SH} \times \mathrm{PL}$ & 1 & 1.67 & 2.39 & 0.29 & 1.43 & 0.05 & 0.46 & $<0.01$ & 0.15 \\
\hline $\mathrm{SH} \times \mathrm{PS}$ & 2 & 2.06 & 2.96 & 0.06 & 0.28 & 0.10 & 0.84 & $<0.01$ & 0.66 \\
\hline $\mathrm{SR} \times \mathrm{SH} \times \mathrm{PL}$ & 1 & 2.01 & 2.87 & 0.00 & 0.01 & 0.00 & 0.01 & $<0.01$ & 0.86 \\
\hline $\mathrm{SR} \times \mathrm{SH} \times \mathrm{PS}$ & 2 & 0.66 & 0.94 & 0.24 & 1.20 & 0.03 & 0.28 & $<0.01$ & 0.93 \\
\hline Residual & $210^{\mathrm{a}}$ & 0.70 & & 0.20 & & 0.12 & & & \\
\hline KA & 1 & 14.31 & $19.96 * *$ & 12.03 & $58.72 * *$ & 23.91 & $212.05 * *$ & $<0.01$ & $107.17 * * *$ \\
\hline $\mathrm{SR} \times \mathrm{KA}$ & 1 & 0.56 & 0.78 & 0.02 & 0.11 & 0.08 & 0.71 & $<0.01$ & 3.49 \\
\hline $\mathrm{TH} \times \mathrm{KA}$ & 1 & 0.00 & 0.00 & 0.01 & 0.04 & 0.18 & 1.56 & $<0.01$ & 0.17 \\
\hline $\mathrm{TH} \times \mathrm{PS}$ & 2 & 1.69 & 2.35 & 0.15 & 0.74 & 0.10 & 0.89 & $<0.01$ & 0.75 \\
\hline $\mathrm{SR} \times \mathrm{TH} \times \mathrm{KA}$ & 1 & 0.02 & 0.02 & 0.0 & 0.03 & 0.37 & 3.31 & $<0.01$ & 0.56 \\
\hline $\mathrm{SR} \times \mathrm{TH} \times \mathrm{PS}$ & 2 & 0.87 & 1.22 & 0.07 & 0.33 & 0.21 & 1.84 & $<0.01$ & 0.45 \\
\hline Residual & $210^{\mathrm{a}}$ & 0.72 & & 0.20 & & & 0.11 & & \\
\hline $\mathrm{TP}$ & 1 & 25.83 & $37.88 * *$ & 1.38 & $7.56 * *$ & 1.56 & $14.17 * *$ & $<0.01$ & $144.96 * * *$ \\
\hline $\mathrm{SR} \times \mathrm{TP}$ & 1 & 0.56 & 0.82 & 0.05 & 0.28 & 0.05 & 0.49 & $<0.01$ & $6.25^{*}$ \\
\hline $\mathrm{LG} \times \mathrm{TP}$ & 1 & 8.17 & $11.97^{* *}$ & 2.56 & $14.02 * *$ & 0.44 & $3.97^{*}$ & $<0.01$ & $7.61 * *$ \\
\hline $\mathrm{LG} \times \mathrm{PS}$ & 2 & 0.76 & 1.11 & 0.82 & $4.50 *$ & 0.06 & 0.51 & $<0.01$ & 2.35 \\
\hline $\mathrm{SR} \times \mathrm{LG} \times \mathrm{TP}$ & 1 & 0.55 & 0.81 & 0.16 & 0.89 & 0.54 & $4.89 *$ & $<0.01$ & 0.77 \\
\hline $\mathrm{SR} \times \mathrm{LG} \times \mathrm{PS}$ & 2 & 1.16 & 1.71 & 0.45 & 2.45 & 0.31 & 2.78 & $<0.01$ & 2.53 \\
\hline Residual & $210^{\mathrm{a}}$ & 0.68 & & 0.18 & & 0.11 & & $<0.01$ & \\
\hline
\end{tabular}
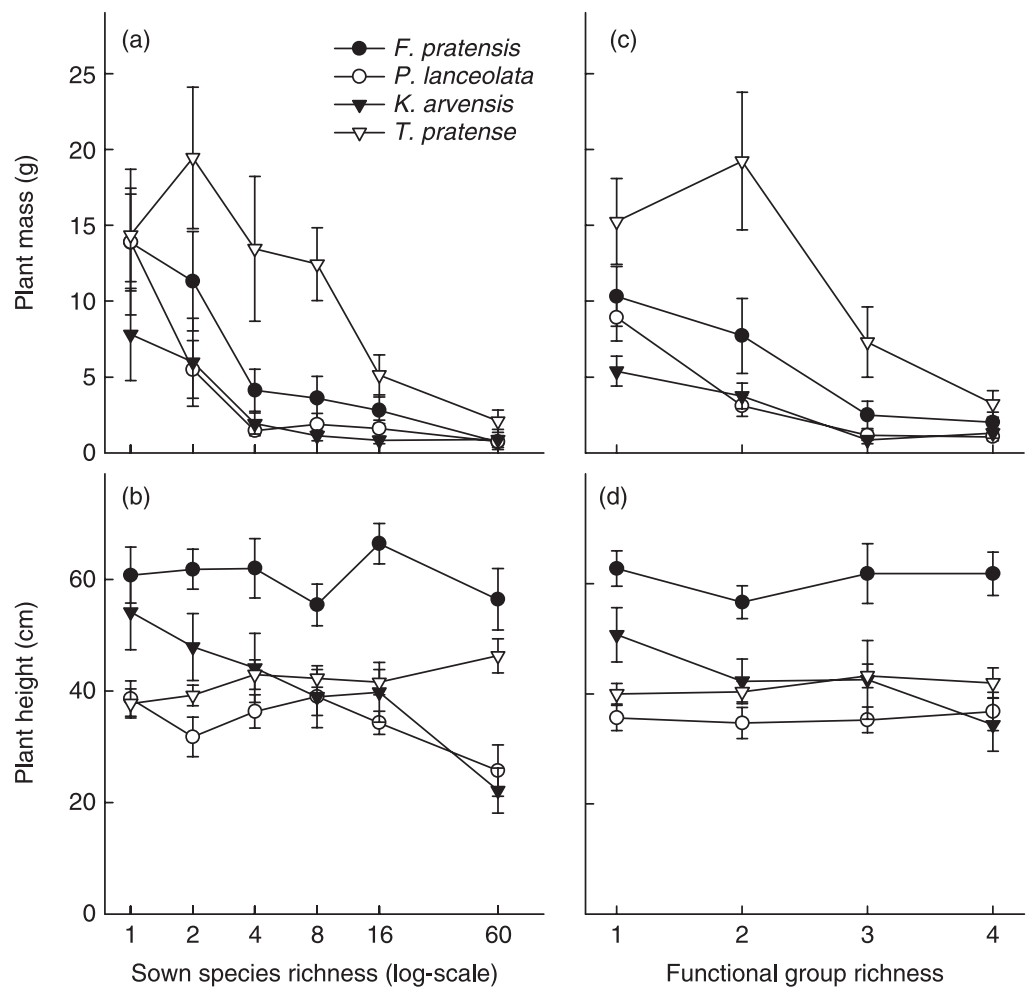

Fig. 2 Effect of plant species richness (a-b) and functional group richness (c-d) on performance of four transplanted phytometer species in the second season (spring 2004). Points and vertical bars represent means \pm 1 standard error. All panels use the legend in panel (a). 
P. N. Mwangi et al.

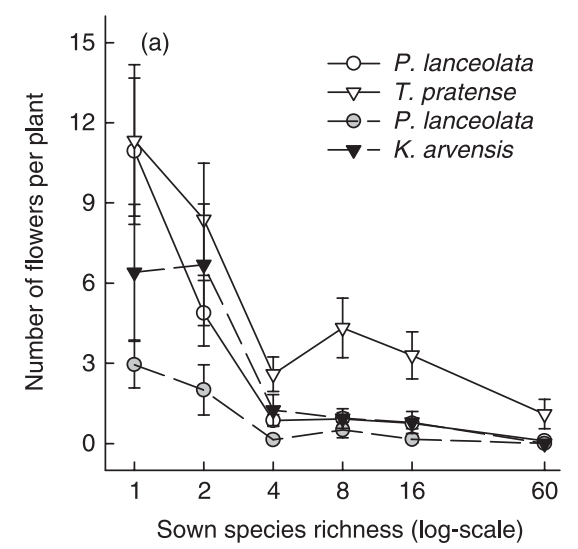

(b)

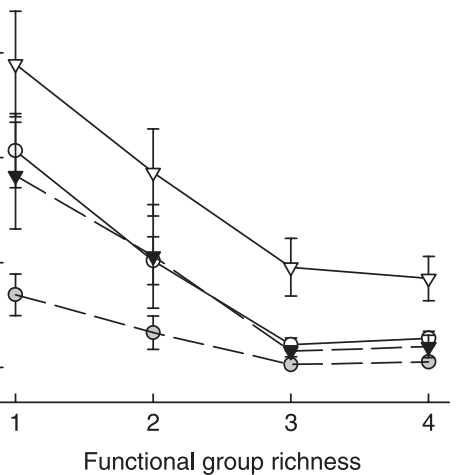

Fig. 3 Effect of plant species richness (a) and functional groups richness (b) on number of inflorescences of four transplanted phytometer species in summer 2003 (solid lines) and spring 2004 (broken lines). Points and vertical bars represent means \pm 1 standard error.

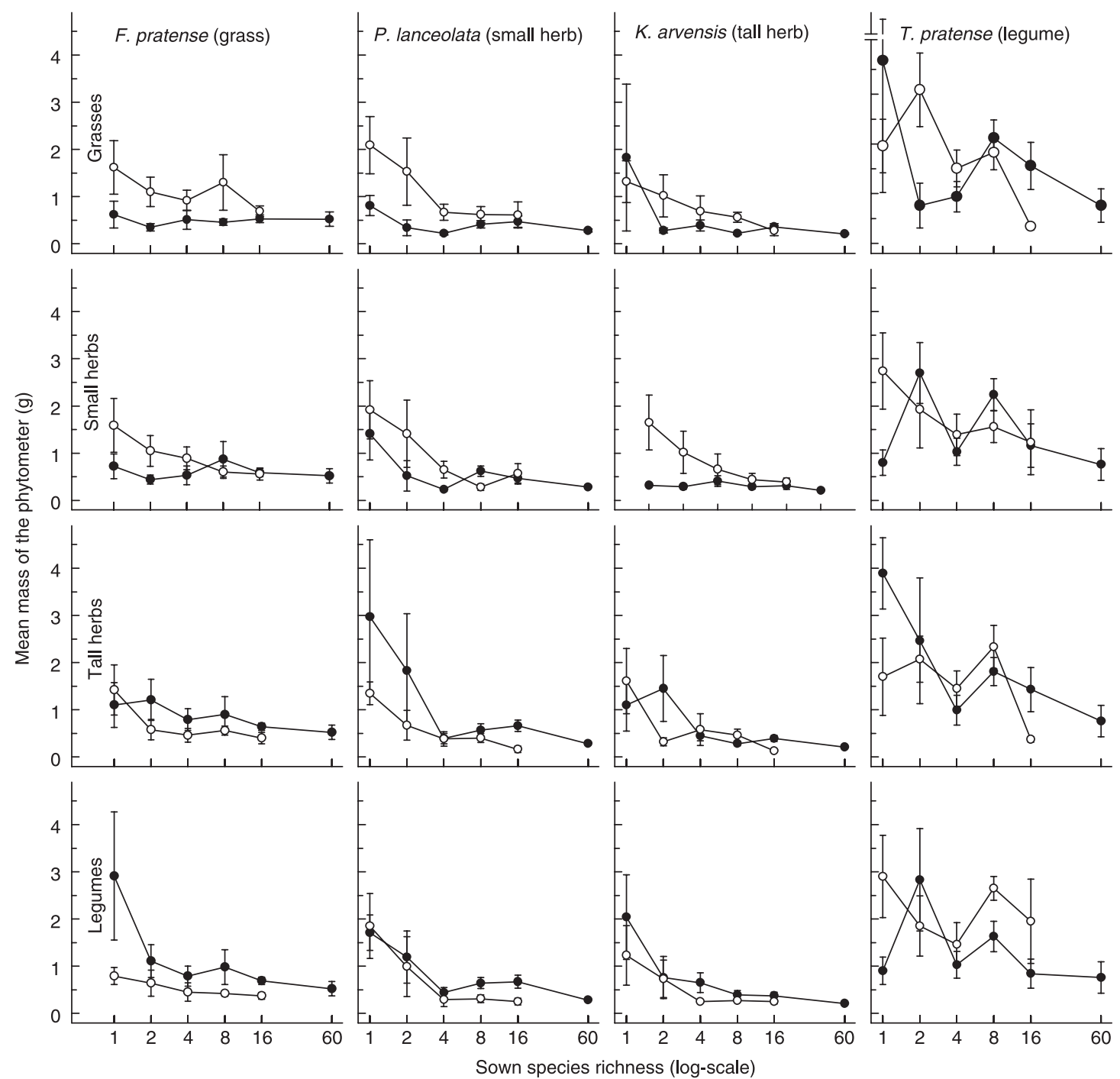

(C) 2006 The Authors Journal compilation (C) 2006 British Ecological Society, Journal of Ecology 95, 65-78
Fig. 4 Effect of plant species richness and presence/absence of different functional groups on biomass of four transplanted phytometer species in the first season (summer 2003). Columns represent phytometers species $F$. pratensis, $P$. lanceolata, $K$. arvensis and $T$. pratense from left to right and rows represent presence/absence of grasses, small herbs, tall herbs and legumes from top to bottom. Closed and open symbols indicate, respectively, presence and absence of the corresponding functional groups in the resident communities. For example, the second panel in the first row shows the response of $P$. lanceolata to species richness in the plots containing grasses (closed symbols) and in plots without grasses (open symbols). Points and vertical bars represent means \pm 1 standard error. 
73

Niche pre-emption and invasion

resistance
(C) 2006 The Authors Journal compilation (C) 2006 British Ecological Society, Journal of Ecology 95, 65-78
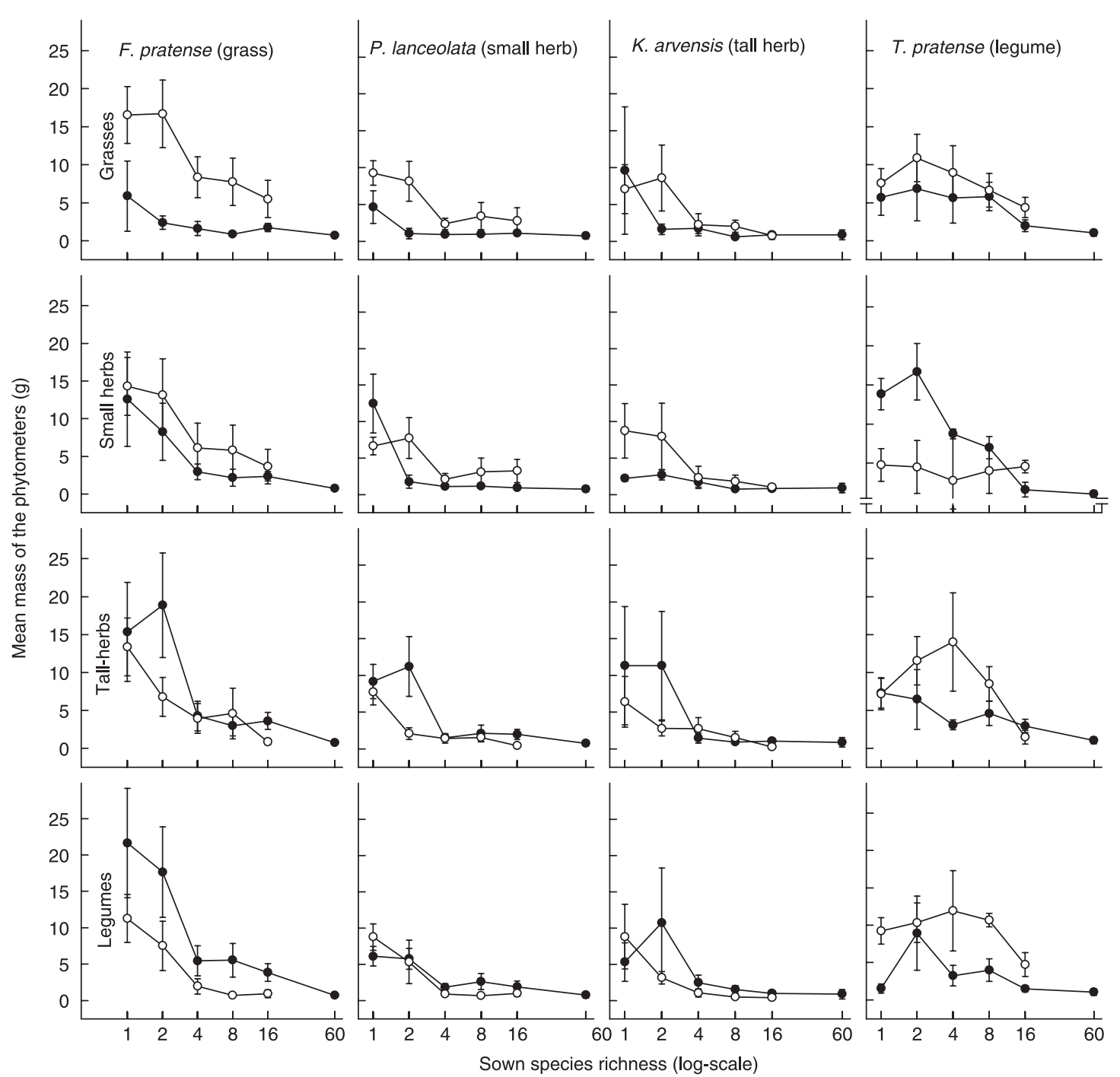

Fig. 5 Effects of plant species richness and presence/absence of different functional groups on biomass of four transplanted phytometer species in the second season (spring 2004). Columns represent phytometers species F. pratensis, P. lanceolata, $K$ arvensis and $T$. pratense from left to right and rows represent presence/absence of grasses, small herbs, tall herbs and legumes from top to bottom. Closed and open symbols indicate, respectively, presence and absence of functional groups in the resident communities. Points and vertical bars represent means \pm 1 standard error.

(T. pratense) phytometer were more affected by these differences. This is evident in Fig. 5 by comparing differences between open and filled symbols in monocultures. A contrast between monocultures vs. multispecies assemblages containing one functional group showed that the number of modules (leaves or ramets), above-ground biomass and growth rate of the phytometers were significantly lower in the latter (Table 3). This reinforces the statistical observation made above, that competitive suppression increases with species richness of a community even if functional richness is held constant, in this case at the lowest level. The homedisadvantage was similar in mono-specific and multispecies single-functional-group assemblages (interaction home $\times$ mono not significant in Table 3 ).

Except for plant height, the home vs. away contrast almost fully explained the resident functional groupphytometer species interactions (Table 3). That is, as predicted, the phytometers had significantly lower performance when transplanted into assemblages consisting of the same rather than a different functional group (the effects of home-functional groups were stronger than of away-functional groups, i.e. negative bars in Fig. 6). The significant residual RFG-PS interaction for plant height indicates that the home effect on plant height is not as clear-cut; for example, F. pratense phytometers were taller in non-grass single function group assemblages, whereas $T$. pratense phytometers were shorter in non-legume single functional group assemblages (Fig. 6). The four-phytometer species responded differently to mono-specific vs. multispecies single-functional-group assemblages (Table 3): the biomass of $P$. lanceolata declined from $5.3 \mathrm{~g}$ in monospecific to $0.9 \mathrm{~g}$ in multispecies single-functional-group assemblages, whereas the other three-phytometer species showed little reduction in above-ground biomass. For two-phytometer species that also occurred as monocultures, $P$. lanceolata was greatly suppressed by 
74

P. N. Mwangi et al.
Table 3 Summary of analyses of variance of summer 2003 data for home vs. away effect on the four phytometer species using plots with resident communities consisting of species from only one functional group. Significance levels are $* P<0.05,{ }^{* *} P<0.01$, $* * * P<0.001$ its own monoculture in both seasons. It attained less than $1.5 \mathrm{~g}$ in its own monoculture in both seasons compared with an average of $5.6 \mathrm{~g}$ and $14.7 \mathrm{~g}$ in other monocultures in summer 2003 and spring 2004, respectively. By contrast, $F$. pratense performed well in its own monocultures especially in 2004 (i.e. $19.6 \mathrm{~g}$ in its own and $13.5 \mathrm{~g}$ in others).

\section{Discussion}

EFFECTS OF SPECIES RICHNESS AND FUNCTIONAL RICHNESS

By introducing young plants of native species as test invaders into host communities, we have shown that plant diversity enhances competitive suppression of newly arriving individuals during the invasion process. This supports the proposition that species-rich communities contain less empty niches that can be occupied by extra individuals. The performance of the test invaders in our experiment was linearly related to the logarithm of species richness. This indicates an attenuation of invasion resistance in more diverse host communities, probably due to increased niche overlap among resident species. It is conceivable that stronger invasion resistance could have been observed if we had introduced seeds (see, e.g. Symstad 2000; Dukes 2001) instead of young plants, but then we would have confounded requirements for empty germination niches with those for growing plants. Our results agree with several previous findings referring to invasions by non-native species (e.g. Levine 2000; Prieur-Richard et al. 2002). With one of the most balanced designs in terms of species and functional diversity achieved so far in biodiversity experiments (Roscher et al. 2004), our results show that in contrast to previous suggestions (Diaz \& Cabido 2001) species richness was a better predictor of invasion resistance than was functional group richness.

As functional groups are aggregations of species, three

observations (that can apply in natural communities) may explain why the effect of species richness in this study was stronger than that of functional group richness. First, aggregating several species into few functional groups makes species richness have a wider range (1-60 species) than functional richness (14 functional groups). Secondly, differential effects of functional richness on different phytometer species leads to an averaging of the overall effect of functional richness in a balanced design, where each functional group is represented equally among the four phytometer species and among the resident plant communities. A case in point is the positive effect of resident legumes on non-legume test-invaders and the negative effect on the legume test-invader. Thirdly, contrasting effects of different functional groups on resources may weaken the overall effect of functional group richness. For example, while legumes enrich soil with nitrogen, grasses deplete this resource (Tilman et al. 1997; Scherer-Lorenzen et al. 2003). These counteracting effects of functional groups on resource pre-emption weaken the overall effect of functional group richness on suppression of test-invaders, supporting resource pre-emption as one mechanism of invasion resistance in plant communities.

Nonetheless, as in the study by Symstad (2000), using seeds instead of transplants as invaders, functional group richness can enhance invasion resistance, if considered alone. Interestingly, Symstad (2000) could not attribute increased invasion resistance by functionally rich communities to resource pre-emption, which indicates that in her case perhaps specific requirements for germination played an important role. Our study showed that pure grass mixtures could be most resistant to invasion after germination, underlying the importance of traits of specific groups (see next section). It remains debatable, of course, whether the a priori definitions of functional groups that we adopted in The Jena Experiment are adequate to understand the relationship between functional diversity and invasion resistance. Nevertheless, the fact that species
Journal of Ecology 95, 65-78
(C) 2006 The Authors Journal compilation (C) 2006 British Ecological Society, 
Niche pre-emption and invasion resistance

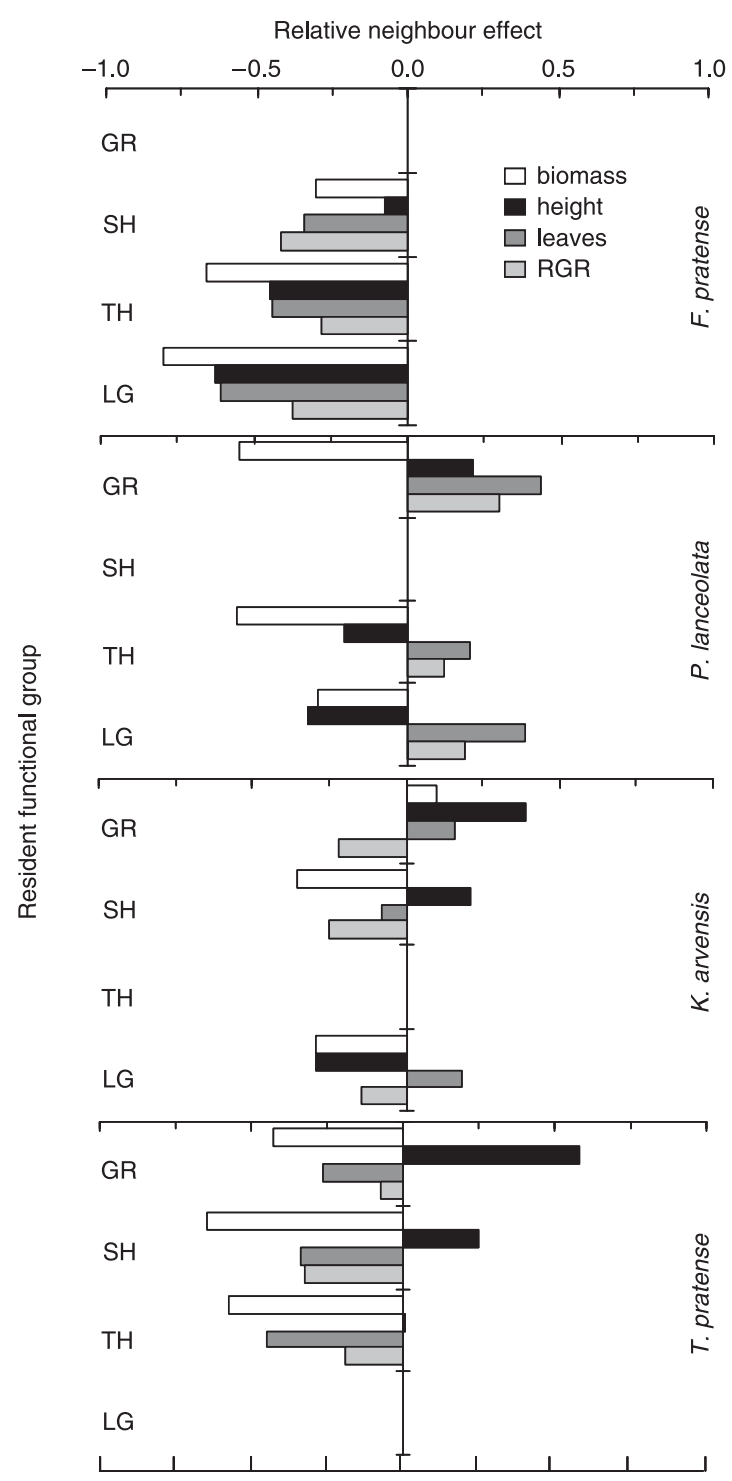

Fig. 6 Performance of phytometers transplanted into singlefunctional-group assemblages of grasses (GR), small herbs $(\mathrm{SH})$, tall herbs $(\mathrm{TH})$ and legumes (LG) relative to performance in mono-functional group assemblages of their own functional group. Negative values indicate negative 'home' effects, i.e. that resident species belonging to a functional group different from that of the phytometer were less inhibitive, while positive values indicate positive home effects.

richness log-linearly increased invasion resistance even within plant assemblages consisting of a single functional group further exemplifies the importance of species richness as a driver in this particular case of an ecosystem function.

\section{EFFECTS OF THE PRESENCE OF PARTICULAR} FUNCTIONAL GROUPS

Journal compilation (C) 2006 British Ecological Society, Journal of Ecology 95, 65-78

The negative, positive and neutral effect of legumes, in our study reflects their known patterns of resource use (Fargione et al. 2003; Fargione \& Tilman 2005) and fits with a general theory of invasibility of Davis et al. (2000). In our experiment, better performance of the phytometers in communities with legumes corresponded with findings that they actually benefited from nitrogen fixed by legumes (Temperton et al. 2006). It is well documented that legumes, by adding nitrogen to the soil, can promote invasion in nitrogen-limited environments (Yelenik et al. 2004 and references therein). By actively fixing atmospheric nitrogen, legumes do not rely on soil-nitrogen pools. Thus, a related effect of legumes is the reduction of competition for soil nitrogen. Some previous studies, however, have reported increased invasion resistance due to presence of legumes (Hector et al. 2001; Fargione et al. 2003). It is notable that positive effects of legumes usually correlate with their effect on below-ground resources, mainly soil nitrogen (Maron \& Connors 1996; PrieurRichard et al. 2002), while their negative effects usually correlate with their effect on above-ground resources (Hector et al. 2001; Fargione et al. 2003). Thus, in general, legumes may enhance invasion resistance in fertile soils but promote invasion in poor soils. In addition, legumes may have a stronger potential than grasses and herbs to differentially affect different invaders. Notably, as mentioned above, they can have negative effects on other legumes even when they have positive effects on other species.

Suppression of all phytometers was particularly strong in resident communities containing grasses. Due to their extensive root systems, grasses are efficient in taking up resources from the upper soil layers (Fargione et al. 2003), thereby diminishing resources for potential invaders. Other studies have also reported grasses as a keystone functional group reducing the success of invaders (Crawley et al. 1999; Dukes 2002; Prieur-Richard et al. 2002). Crawley et al. (1999) found that an assembly of 80 herbaceous species was more vulnerable to invasion than were assemblies composed of one to four grass species. A weak effect of grasses on LAI did not explain the strong negative effect of their presence on invasion resistance, suggesting that their contribution to invasion resistance is mainly through their effect on below-ground resources. From these results we can conclude that with regard to functional diversity, functional group identity may be more important than pure number of functional groups (Schmid et al. 2002). This was also observed in the same experiment by Scherber et al. (2006), investigating herbivory on a different phytometer species, Rumex acetosa.

EFFECTS OF THE FUNCTIONAL GROUP OF THE PHYTOMETER SPECIES AND NICHE PRE-EMPTION WITHIN FUNCTIONAL GROUPS AS MAJOR MECHANISM OF INVASION RESISTANCE
With regard to the identity of the invader, experimental communities were particularly resistant to a phytometer 
P. N. Mwangi et al. species if they contained species belonging to the same functional group. For example, although non-legume herbs had no effect on invasion resistance in general, their presence in the resident communities enhanced suppression of their respective phytometers. Likewise, despite notable facilitation by legumes, communities containing only this functional group strongly inhibited the legume test invader, $T$. pratense. Our results and a previous observation that legume monocultures were most resistant to invasion by legumes (Turnbull et al. 2005) indicate that resident legumes also preempt other resources that limit legumes, most likely phosphorus, water and light (Vitousek \& Howarth 1991). This is consistent with high niche overlap along several resource-use axes between resident and invading legumes, and further supports niche pre-emption as a mechanism of invasion resistance. Thus, high niche overlap between newly arriving individuals and resident species can reduce chances of an invasion, rate of colonization or even success of restoration. This corresponds to findings of Fargione et al. (2003) in a seed addition experiment, where they concluded that high invasion resistance was due to similar patterns of resource use between the resident species and the invaders. Xu et al. (2004) also found that the presence of a functionally similar herb in a resident community increased resistance to invasion by Alligator weed (Alternanthera philoxeroides), which was also attributed to niche overlap.

Finally, it should be mentioned that alternative hypotheses might also be consistent with the result of stronger within- than between-functional-group invasion resistance (Fukami et al. 2005; BrittonSimmons 2006). Namely, the presence of a species in a community might build up pathogens, parasites or herbivores that have negative impacts on invaders from the same functional group (Wardle et al. 2004; BarteltRyser et al. 2005). It is conceivable that such effects are particularly important during the early phases of the life cycle of invaders, e.g. during germination. However, in this study we could not test this because we introduced our test invaders as young plants rather than seeds into the communities.

This study confirms that, first, communities that are more diverse confer high resistance to invasion independent of invasiveness of the introduced species. Secondly, presence of grasses enhances invasion resistance while legumes may promote invasion due to their influence on nitrogen dynamics. Thirdly, communities are more resistant to invaders belonging to functional groups already present among the resident species. Although these results pertain to grassland ecosystems that are regularly 'disturbed' by mowing, similar mechanisms may play a role in other terrestrial and in aquatic ecosystems where species richness has been shown to increase invasion resistance (see review by Balvanera et al. 2006). However, to our knowledge this has not been investigated in such a systematic way as we did here in grassland systems.

\section{Acknowledgements}

We are grateful to the gardeners and numerous helpers who assisted in weeding and maintenance of experimental plots. Thanks to Christina Fischer, Anne Froehlich and Anja Dassler for their assistance in the field and laboratory. Ernst-Detlef Schulze guided the development of the Jena Experiment and of this project. We are grateful for the comments from two anonymous reviewers. This research was supported by grants from the German Science Foundation (grant no. FOR 456 - WE 2618/6-1 to W.W.W and B.S) and the Swiss National Science Foundation (grant no. 31-65224.01 to B.S) and by the Friedrich-SchillerUniversity of Jena and the Max-Planck-Institute for Biogeochemistry, Jena.

\section{References}

Balvanera, P., Pfisterer, A.B., Buchmann, N., He, J.-S., Nakashizuka, T., Raffaelli, D. et al. (2006) Quantifying the evidence for biodiversity effects on ecosystem functioning and services. Ecology Letters, 9, 1146-1156.

Bartelt-Ryser, J., Joshi, J., Schmid, B., Brandl, H. \& Balser, T. (2005) Soil feedbacks of plant diversity on soil microbial communities and subsequent plant growth. Perspectives in Plant Ecology, Evolution and Systematics, 7, 27-49.

Bossdorf, O., Prati, D., Auge, H. \& Schmid, B. (2004) Reduced competitive ability in an invasive plant. Ecology Letters, 7, 346-353.

Britton-Simmons, K.H. (2006) Functional group diversity, resource preemption and the genesis of invasion resistance in a community of marine algae. Oikos, 113, 395-401.

Clements, F.E. \& Goldsmith, G.W. (1924) The Phytometer Method in Ecology: the Plant and Community as Instruments. The Carnegie Institution, Washington, DC.

Colautti, R.I., Ricciardi, A., Grigorovich, I.A. \& MacIsaac, H.J. (2004) Is invasion success explained by the enemy release hypothesis? Ecology Letters, 7, 721-733.

Crawley, M.J., Brown, S.L., Heard, M.S. \& Edwards, G.R. (1999) Invasion-resistance in experimental grassland communities: species richness or species identity? Ecology Letters, 2, 140-148.

Davis, M.A., Grime, J.P. \& Thompson, K. (2000) Fluctuating resources in plant communities: a general theory of invasibility. Journal of Ecology, 88, 528-534.

Diaz, S. \& Cabido, M. (2001) Vive la difference: plant functional diversity matters to ecosystem processes. Trends in Ecology and Evolution, 16, 646-655.

Diemer, M. \& Schmid, B. (2001) Effects of biodiversity loss and disturbance on the survival and performance of two Ranunculus species with differing clonal architectures. Ecography, 24, 59-67.

Dimitrakopoulos, P.G. \& Schmid, B. (2004) Biodiversity effects increase linearly with biotope space. Ecology Letters, 7, 574-583.

Dukes, J.S. (2001) Biodiversity and invasibility in grassland microcosms. Oecologia, 126, 563-568.

Dukes, J.S. (2002) Species composition and diversity affect grassland susceptibility and response to invasion. Ecological Applications, 12, 602-617.

Elton, C.S. (1958) The Ecology of Invasions by Animals and Plants. Methuen, London.

Fargione, J., Brown, C.S. \& Tilman, D. (2003) Community assembly and invasion: an experimental test of neutral versus niche processes. Proceedings of the National Academy of Sciences of the USA, 100, 8916-8920.
Journal of Ecology

95, 65-78
(C) 2006 The Authors ournal compilation (C) 2006 British Ecological Society, 
Niche pre-emption and invasion resistance

(C) 2006 The Authors Journal compilation (C) 2006 British Ecological Society, Journal of Ecology 95, 65-78
Fargione, J.E. \& Tilman, D. (2005) Diversity decreases invasion via both sampling and complementarity effects. Ecology Letters, 8, 604-611.

Fukami, T., Bezemer, T.M., Mortimer, S.R. \& van der Putten, W.H. (2005) Species divergence and trait convergence in experimental plant community assembly. Ecology Letters, 8, 1283-1290.

Garnier, E., Cortez, J., Billes, G., Navas, M.L., Roumet, C., Debussche, M. et al. (2004) Plant functional markers capture ecosystem properties during secondary succession. Ecology, 85, 2630-2637.

Harper, J.L. (1977) Population Biology of Plants. Academic Press, London.

Hector, A., Dobson, K., Minns, A., Bazeley-White, E. \& Lawton, J.H. (2001) Community diversity and invasion resistance: an experimental test in a grassland ecosystem and a review of comparable studies. Ecological Research, 16, 819-831.

Heemsbergen, D.A., Berg, M.P., Loreau, M., van Haj, J.R., Faber, J.H. \& Verhoef, H.A. (2004) Biodiversity effects on soil processes explained by interspecific functional dissimilarity. Science, 306, 1019-1020.

Hierro, J.L., Maron, J.L. \& Callaway, R.M. (2005) A biogeographical approach to plant invasions: the importance of studying exotics in their introduced and native range. Journal of Ecology, 93, 5-15.

Hutchinson, G.E. (1957) Population studies - animal ecology and demography - concluding remarks. Cold Spring Harbor Symposia on Quantitative Biology, 22, 415-427.

Joshi, J., Matthies, D. \& Schmid, B. (2000) Root hemiparasites and plant diversity in experimental grassland communities. Journal of Ecology, 88, 634-644.

Joshi, J., Schmid, B., Caldeira, M.C., Dimitrakopoulos, P.G., Good, J., Harris, R. et al. (2001) Local adaptation enhances performance of common plant species. Ecology Letters, $\mathbf{4}$, $536-544$.

Kennedy, T.A., Naeem, S., Howe, K.M., Knops, J.M.H., Tilman, D. \& Reich, P. (2002) Biodiversity as a barrier to ecological invasion. Nature, 417, 636-638.

Knops, J.M.H., Tilman, D., Haddad, N.M., Naeem, S., Mitchell, C.E., Haarstad, J. et al. (1999) Effects of plant species richness on invasion dynamics, disease outbreaks, insect abundances and diversity. Ecology Letters, 2, 286-293.

Levine, J.M. (2000) Species diversity and biological invasions: relating local process to community pattern. Science, $\mathbf{2 8 8}$, 852-854.

Levine, J.M. \& D'Antonio, C.M. (1999) Elton revisited: a review of evidence linking diversity and invasibility. Oikos, 87, 15-26.

MacArthur, R. (1970) Species-packing and competitive equilibrium for many species. Theoretical Population Bio$\log y, \mathbf{1}, 1-11$.

Markham, J.H. \& Chanway, C.P. (1996) Measuring plant neighbour effects. Functional Ecology, 10, 548-549.

Maron, J.L. \& Connors, P.G. (1996) A native nitrogen-fixing shrub facilitates weed invasion. Oecologia , 105, 302-312.

Meiners, S.J., Cadenasso, M.L. \& Pickett, S.T.A. (2004) Beyond biodiversity: individualistic controls of invasion in a self-assembled community. Ecology Letters, 7, 121-126.

Naeem, S., Knops, J.M.H., Tilman, D., Howe, K.M., Kennedy, T. \& Gale, S. (2000) Plant diversity increases resistance to invasion in the absence of covarying extrinsic factors. Oikos, 91, 97-108.

Payne, R.W., Baird, D.B., Gilmour, A.R., Harding, S.A., Lane, P.W., Murray, D.A. et al. (2002) GenStat Release 6.1 Reference Manual. VSN International, Oxford.

Petchey, O.L., Hector, A. \& Gaston, K.J. (2004) How do different measures of functional diversity perform? Ecology, 85, 847-857.

Pfisterer, A.B., Joshi, J., Schmid, B. \& Fischer, M. (2004) Rapid decay of diversity-productivity relationships after invasion of experimental plant communities. Basic and Applied Ecology, 5, 5-14.

Prieur-Richard, A.-H., Lavorel, S., Dos Santos, A. \& Grigulis, K. (2002) Mechanisms of resistance of Mediterranean annual communities to invasion by Conyza bonariensis: effects of native functional composition. Oikos, 99, 338-346.

Prieur-Richard, A.H., Lavorel, S., Grigulis, K. \& Dos Santos, A. (2000) Plant community diversity and invasibility by exotics: invasion of Mediterranean old fields by Conyza bonariensis and Conyza canadensis. Ecology Letters, 3, 412-422.

Pysek, P., Jarosik, V. \& Kucera, T. (2002) Patterns of invasion in temperate nature reserves. Biological Conservation, 104, 13-24.

Roscher, C., Schumacher, J., Baade, J., Wilcke, W., Gleixner, G., Weisser, W.W. et al. (2004) The role of biodiversity for element cycling and trophic interactions: an experimental approach in a grassland community. Basic and Applied Ecology, 5, 107-121.

Scherber, C., Milcu, A., Partsch, S., Scheu, S. \& Weisser, W.W. (2006) The effects of plant diversity and insect herbivory on performance of individual plant species in experimental grassland. Journal of Ecology, 94, 922-931.

Scherer-Lorenzen, M., Palmborg, C., Prinz, A. \& Schulze, E.D. (2003) The role of plant diversity and composition for nitrate leaching in grasslands. Ecology, 84, 1539-1552.

Schmid, B., Hector, A., Huston, M.A., Inchausti, P., Nijs, I., Leadley, P.W. et al. (2002) The design and analysis of biodiversity experiments. Biodiversity and Ecosystem Functioning Synthesis and Perspectives (eds M. Loreau, S. Naeem \& P. Inchausti), pp. 61-75. Oxford University Press, Oxford.

Shea, K. \& Chesson, P. (2002) Community ecology theory as a framework for biological invasions. Trends in Ecology and Evolution, 17, 170-176.

Stadler, J., Trefflich, A., Klotz, S. \& Brandl, R. (2000) Exotic plant species invade diversity hot spots: the alien flora of northwestern Kenya. Ecography, 23, 169-176.

Stohlgren, T.J., Binkley, D., Chong, G.W., Kalkhan, M.A., Schell, L.D., Bull, K.A. et al. (1999) Exotic plant species invade hot spots of native plant diversity. Ecological Monographs, 69, 25-46.

Stohlgren, T.J., Chong, G.W., Schell, L.D., Rimar, K.A., Otsuki, Y., Lee, M. et al. (2002) Assessing vulnerability to invasion by nonnative plant species at multiple spatial scales. Environmental Management, 29, 566-577.

Symstad, A.J. (2000) A test of the effects of functional group richness and composition on grassland invasibility. Ecology, 81, 99-109.

Temperton, V.M., Mwangi, P.N., Scherer-Lorenzen, M., Schmid, B. \& Buchmann, N. (2006) Positive interactions between nitrogen-fixing legumes and four different neighbouring species in a biodiversity experiment. Oecologia, in press.

Tilman, D. (1997) Community invasibility, recruitment limitation, and grassland biodiversity. Ecology, 78, 81-92.

Tilman, D. (1999) The ecological consequences of changes in biodiversity: a search for general principles. Ecology, 80, 1455-1474.

Tilman, D., Knops, J., Wedin, D., Reich, P., Ritchie, M. \& Siemann, E. (1997) The influence of functional diversity and composition on ecosystem processes. Science, 277, $1300-1302$.

Troumbis, A.Y., Galanidis, A. \& Kokkoris, G.D. (2002) Components of short-term invasibility in experimental Mediterranean grasslands. Oikos, 98, 239-250.

Turnbull, L.A., Rahm, S., Baudois, O., Eichenberger-Glinz, S., Wacker, L. \& Schmid, B. (2005) Experimental invasion by legumes reveals non-random assembly rules in grassland communities. Journal of Ecology, 93, 1062-1070.

Vila, M. \& Weiner, J. (2004) Are invasive plant species better competitors than native plant species? Evidence from pairwise experiments. Oikos, 105, 229-238. 
78

P. N. Mwangi et al.

Vitousek, P.M. \& Howarth, R.W. (1991) Nitrogen limitation on land and in the sea: how can it occur? Biogeochemistry, 13, 87-115.

Wardle, D.A., Bardgett, R.D., Klironomos, J.N., Setala, H., van der Putten, W.H. \& Wall, D.H. (2004) Ecological linkages between aboveground and belowground biota. Science, 304, 1629-1633.

Xu, K., Ye, W., Cao, H., Deng, X., Yang, Q. \& Z. (2004) The role of diversity and functional traits of species in commu- nity invasibility. Botanical Bulletin of Academia Sinica, $\mathbf{4 5}$, 149-157.

Yelenik, S.G., Stock, W.D. \& Richardson, D.M. (2004) Ecosystem level impacts of invasive Acacia saligna in the South African Fynbos. Restoration Ecology, 12, 44-51.

Received 25 June 2006

revision accepted 22 August 2006

Handling Editor: Bryan Foster 